DOI 10.37882/2223-2982.2020.05.15

\title{
РЕАЛИЗАЦИЯ ПРОБЛЕМНО-ЭВРИСТИЧЕСКОГО ОБУЧЕНИЯ В ПРЕПОДАВАНИИ МАТЕМАТИЧЕСКИХ ДИСЦИПЛИН В ОБРАЗОВАТЕЛЬНЫХ ОРГАНИЗАЦИЯХ ВЫСШЕГО ОБРАЗОВАНИЯ
}

\section{IMPLEMENTATION OF PROBLEM- HEURISTIC LEARNING IN TEACHING MATHEMATICAL DISCIPLINES AT HIGHER EDUCATION INSTITUTIONS \\ E. Kosheleva L. Proskuryakova}

Summary: The article emphasizes the feasibility of implementing the ideas and methods of both problem-oriented and heuristic teaching at the organization of the educational and cognitive activities. Attention is paid to introducing students to the search and research activities in the while implementing problem-heuristic training. The advantages and disadvantages of problem-heuristic training while teaching mathematics at higher education institutions are described.

Keywords: problem issue, problem situation, educational problem, problem learning, heuristic teaching, problem-heuristic teaching, productive thinking, heuristic (creative) thinking. Если ученик ... не научился сам ничего творить, то и в жизни
в всегда будет только подражать, копировать, так как мало
таких, которые бы, научившись копировать, умели сделать самостоятельное приложение этих сведений.

Л. Н. Толстой

$\mathrm{O}$ бразование в современной России занимает одно из ведущих мест среди факторов развития страны и является объектом государственной политики. Выдвинутое правительством РФ направление инновационного обновления образования преследует значимые для государства цели - повышение уровня образования, обеспечение качества знаний выпускников образовательных учреждений, увеличение числа квалифицированных специалистов.

Разработанная Национальная доктрина образования в Российской Федерации до 2025 года, особая роль в которой отведена самосовершенствованию и самоактуализации личности, способствует созданию в образовательных учреждениях специальных условий, программ и проектов, которые преследуют цели реализации, в том числе, творческого потенциала будущих специалистов и развития их исследовательских способностей [14].

\author{
Кошелева Елена Алексеевна \\ К.п.н., Академия Федеральной службы охраны России, \\ 2. Орел \\ nneo2010.lena@yandex.ru \\ Проскурякова Людмила Константиновна \\ К.п.н., дочент, Академия Федеральной службы охраны \\ России, г. Орел
}

Аннотация: В статье подчеркивается целесообразность внедрения в организацию учебно-познавательной деятельности идей и методов проблемноориентированного и эвристического обучений. Уделено внимание приобщению обучающихся к поисковой и исследовательской деятельности в процессе реализации проблемно-эвристического обучения. Охарактеризованы преимущества и недостатки проблемно-эвристического обучения в преподавании математики в вузе.

Ключевые слова: проблемная задача, проблемная ситуация, учебная проблема, проблемное обучение, эвристическое обучение, проблемно-эвристическое обучение, продуктивное мышление, эвристическое (творческое) мышление.

Выпускники отечественных образовательных организаций высшего образования призваны решать сложнейшие технологические и математические задачи, обеспечивающие эффективность функционирования многих отраслей промышленности, исследовательских центров и институтов. Коллективами образовательных организаций высшего образования накоплен богатый опыт использования проблемного обучения, являющегося в современной дидактике высшей школы одним из ведущих и перспективных методов обучения.

Проблемное обучение представляет собой разновидность развивающего обучения, когда процесс взаимодействия преподавания и учения ориентирован на развитие познавательной самостоятельности обучающихся; устойчивых мотивов учебной работы; интеллектуальных, творческих способностей в ходе усвоения научных понятий и способов деятельности, целенаправленно детерминированных системой проблемных ситуаций [11]. Принимая во внимание специфические особенности учебной дисциплины «Математика», можно утверждать, что реализация в ходе ее изучения идей проблемного обучения является одним из важнейших условий успешности развития у обучающихся способ- 
ностей к эвристической деятельности, поскольку «эвристические процессы доминируют в проблемном (эвристическом) обучении» [13].

В преподавании технических и математических дисциплин в вузе эвристическое обучение понимается и как метод, помогающий изучать новые области знаний, и как процесс развития творческого, нестандартного мышления обучающегося, обусловливающий развитие его интеллектуального потенциала.

Идеи эвристического обучения в современной дидактике разрабатывались в трудах М.М. Левиной, А.В. Хуторского. Среди работ, посвященных вопросам развития эвристического метода обучения математике, следует отметить работы В.А. Крутецкого, Д. Пойа, Е.Н. Турецкого, Л.М. Фридмана.

Реализация эвристических подходов к обучению в нашей стране до настоящего времени не была связана с инновационными дидактическими системами. Эвристический аспект обучения более всего оказался присущ проблемному и развивающему обучению.

Для организации проблемно-ориентированного обучения, как обучения, рационально сочетающего идеи и методы проблемного и так называемого «традиционного» обучения (с учетом особенностей изучаемого материала и индивидуальных возможностей обучающихся), важное значение имеет осознание понятия «учебная проблема» и умение подразделять вопросы и задачи на информационные (репродуктивные) и проблемные.

Учебная проблема - это форма возникновения противоречия процесса усвоения, направленная на интеллектуальный поиск с мотивационной составляющей к познанию неизвестного, подводящее к осмыслению нового понятия или нового способа действия.

Проблемными являются те вопросы, которые вызывают у обучающихся интеллектуальные затруднения и требуют серьезного целенаправленного мыслительного процесса, поскольку ответ на них не содержится ни в прежнем багаже знаний обучающихся, ни в предъявляемой преподавателем информации. Они призваны формировать у обучающихся чувство неудовлетворения имеющимся запасом знаний и умений. Тогда как информационные вопросы задаются с целью получения ответов, содержащих лишь известные знания, и, как правило, задействуют лишь память в поисках готовой информации.

Проблемный вопрос, проблемная задача - различные формы выражения учебной проблемы и основные дидактические понятия, оперирование с которыми приводит к возникновению проблемной ситуации и поисковой, эвристической деятельности обучающихся по ее разрешению.

Матюшкин А.М. характеризует проблемную ситуацию как «особый вид умственного взаимодействия объекта и субъекта, характеризующийся таким психическим состоянием субъекта (учащегося) при решении им задач, который требует обнаружения (открытия или усвоения) новых, ранее субъекту неизвестных знаний или способов деятельности « [10]. «Иначе говоря, проблемная ситуация - это такая ситуация, при которой субъект хочет решить какие-то трудные для себя задачи, но ему не хватает данных, и он должен сам их искать» [13].

Создание проблемных ситуаций направлено на достижение следующих целей:

- привлечь внимание обучающихся к изучаемому материалу, возбудить интерес и другие мотивы познавательной деятельности;

- стимулировать осознание возникшего познавательного затруднения, преодоление которого активизировало бы мыслительную деятельность;

- помочь вычленить в учебном задании познавательную проблему и наметить план поиска ее решения, побудив к активной поисковой, эвристической деятельности;

- помочь обучающимся определить границы знаний, усвоенных ранее и востребованных для решения стоящей проблемы, выяснить оптимальные способы ее решения.

Возможность управления учебно-познавательной деятельностью в условиях проблемного обучения состоит в том, что проблемная ситуация в своей структуре имеет не только предметно-содержательную, но и мотивационную, личностную сторону.

Результаты исследований, проведенных И.Я. Лернером [8], Т.В. Кудрявцевым [6], В.Г. Разумовским [16] и др., свидетельствуют о том, что использование метода проблемных ситуаций, по сравнению с так называемыми «традиционными» методами, повышает: интеллектуальный уровень обучающихся [8], коэффициент успешного применения знаний для решения конкретных задач [6], успешность решения творческих задач [16].

Отличительная черта обучения проблемного характера состоит в его глубокой психологической обоснованности. Проблемная ситуация, интерес и эмоциональность - взаимообусловленные явления, которые вместе с волевыми усилиями обучающихся отражают рациональную и чувственную стороны активизации их познавательной деятельности. Кроме того, теория проблемного обучения ставит своей обязательной целью использование собственно психологических закономерностей мышления для управления процессом усвоения знаний.

Психологической основой концепции проблемного 
обучения является теория мышления как продуктивного процесса, выдвинутая С.Л. Рубинштейном. По его мнению, мышление обычно начинается с проблемы или вопроса, с удивления или недоумения, с противоречия. Этой проблемной ситуацией определяется вовлечение личности в мыслительный процесс. Там, где нет проблемной ситуации, нет и мышления в строгом смысле этого слова. Причем, речь идет не о выдумывании и нагромождении искусственных проблем, а об обнаружении и постановке реальных проблем. Первый признак мыслящего человека - это умение видеть проблемы там, где они есть. Недаром о творческом потенциале ученого нередко судят не столько по тем идеям, которые он выдвинул, сколько по характеру проблем, которые он поставил и тем самым очертил контуры будущей науки [17].

Проблемный подход к организации учебно-познавательной деятельности предполагает обязательную реализацию дидактического принципа индивидуального подхода. Суть различия между проблемно-ориентированным и «традиционным» обучением состоит в том, что при «традиционном» обучении потребность в индивидуализации есть следствие диалектического противоречия между фронтальным изложением нового учебного материала преподавателем и индивидуальной формой его восприятия и усвоения обучающимся. Тогда как в проблемно-ориентированном обучении индивидуализация обусловлена, главным образом, наличием учебных проблем разной степени сложности («эвристичности»), которые каждым обучающимся воспринимаются по-разному. Индивидуальное восприятие проблемы вызывает различие в ее формулировании, выдвижении альтернативных гипотез, нахождении различных путей их доказательства.

Теория проблемного обучения математике создавалась и развивалась применительно к общему среднему образованию. Очевидно, что методика проблемного обучения в высшей школе имеет свою специфику, связанную с иными целями и задачами профессиональной подготовки, различиями в возрастных и мотивационных характеристиках школьников и студентов. Нельзя не отметить также специфическую черту учебного процесса в вузе - лекционно-практическую систему занятий вместо классно-урочной, накладывающую свой отпечаток на особенности реализации идей проблемного обучения [4].

Для преподавания математики в контексте приобщения обучающихся к эвристической деятельности значимо то, что проблемно-ориентированное преподавание «основано не на передаче готовой информации, а на получении учащимися новых знаний и умений с помощью решения теоретических и практических проблем. Существенной характеристикой этого преподавания является исследовательская деятельность учащегося, появляющаяся в определенной ситуации и заставляющая его ставить себе вопросы-проблемы, формулировать гипотезы и проверять их в ходе умственных и практических операций» [13].

Основной компонент проблемного подхода состоит в создании условий, при которых у обучающихся возникает потребность в познании - основном источнике психического развития человека. Значимым «условием развития познавательной мотивации учащихся, - по мнению Е.И. Машбиц, - являются проблемные ситуации, стимулирующие преодоление задаваемого прошлым опытом психологического барьера и ведущие к возникновению новых познавательных потребностей» [12].

Одной из задач проблемного подхода к изучению математических дисциплин является четкое отделение того, что обучающиеся знают, от того, что им неизвестно или только кажется известным. «Полузнания» делают обучающегося пассивным и равнодушным. Л.Д. Кудрявцев в числе наиболее существенных недостатков первокурсников, не позволяющих им должным образом изучать высшую математику и затем эффективно применять математические методы в решении прикладных задач, отмечал неумение студентов отличать то, что они понимают от того, что они не понимают; неумение вести диалог: понять вопрос преподавателя и ответить именно на него, корректно сформулировать свой вопрос; стереотипность восприятия информации [7].

По мнению В. Оконя, процесс решения любой достаточно сложной проблемы как типа «открыть», так и типа «создать», как теоретической, так и практической, содержит три фазы:

1. Создание проблемной ситуации.

2. Формирование гипотез разрешения.

3. Проверка решения с систематизацией полученной информации [13].

Реализуя идеи проблемного обучения, преподавателю необходимо учитывать тот факт, что созданная им проблемная ситуация активизирует познавательную деятельность обучающихся лишь тогда, когда разрешение смоделированного интеллектуального затруднения находится в пределах их интеллектуальных возможностей. Вместе с тем Л.С. Выготский писал: «Обучение только тогда хорошо, когда оно идет впереди развития. Тогда оно побуждает и вызывает к жизни целый ряд функций, находящихся в стадии созревания, лежащих в зоне ближайшего развития» [2]. При организации проблемного обучения очень важен подготовительный этап, в ходе которого преподаватель составляет суждение об уровне владения ранее изученным материалом, а также об индивидуальных возможностях обучающихся с тем, чтобы очертить круг проблем, доступных их понимаю, а потому возможных для реализации в учебном процессе.

На этапе создания проблемной ситуации происходит 
постановка практического или теоретического задания, осмысление и анализ проблемной ситуации, в результате чего формулируется конкретная задача, решение которой ведет к открытию обучающимися новых знаний, способов действий.

Используя эвристический подход, анализ проблемы следует начинать с анализа цели, а не с анализа данных. Обучающимся необходимо прививать понимание то, что «решить проблему» означает найти неизвестные. Установка взаимного отношения известных величин позволяет привести к обнаружению недостающего элемента для целостного восприятия решаемой проблемы.

Определив цели и неизвестные, обучающиеся подводятся к постановке гипотез - важная и, одновременно, трудная для них фаза решения проблемы, поскольку формулировка гипотез «... представляет собой процесс эвристического характера и производится по эвристическим правилам (эвристикам)» [13].

До решения какой-либо проблемы целесообразно обучающихся познакомить с эвристиками, особенностями эвристик, эвристическими операциями, приемами и методами и наглядно показать их использование при решении различного рода задач (в том числе практикоориентированных).

Эвристики облегчают формирование гипотез, но они не гарантируют решение проблемы и не имеют такого необходимого характера как алгоритмы, автоматизирующие решение задач до такой степени, что его можно выполнить с использованием компьютеров. Однако алгоритмическое решение далеко не всегда бывает оптимальным, поэтому иногда более экономично применение ненадежных эвристических правил, чем стабильных алгоритмов. Вместе с тем, управляя решением проблемы на этапе выдвижения гипотез, полезно учитывать мнение В. Оконя относительно того, что «процесс формирования гипотез не должен быть следствием «озарений», хотя и это не следует упускать из виду» [13]. При формировании гипотез используются такие эвристические операции, как аналогия, анализ, синтез и др.

Направление поиска гипотез характеризуются известной свободой выбора. Часто применяемое одно из эвристических правил относится и к выбору, и к целесообразности выбора направления, приводившее к решению проблем данного класса. Важное значение имеет то, что предложенная к решению проблема принадлежит к классу проблем, имеющих решение.

В процессе формирования и проверки гипотез значительное внимание уделяется выстроенным умозаключениям. К ним относятся дидуктивные умозаключения (направление от причины к следствию), редуктивные (от следствия к причине); спонтанные умозаключения (от- носятся к эвристическому обучению), умозаключения, направляемые стоящей задачей и зависящие от типа выполняемого задания (доказательство, проверка, объяснение) [13].

На третьей фазе разрешения проблемной ситуации осуществляется проверка выполненного решения, его оценка, систематизация полученной информации и формулировка возможных выводов практического характера. Этот этап особенно важен в математической подготовке инженеров.

Организуя изучение математических дисциплин, важно учитывать мнение А.М. Матюшкина о том, что процессы овладения новыми знаниями и умениями в проблемных ситуациях подчиняются «общим психологическим закономерностям процесса мышления, тогда как конкретные способы создания проблемных ситуаций в различных предметах должны соответствовать общим принципам методики изучения этого предмета» [10].

Так на лекциях проблемные ситуации создаются, в основном, при изучении теоретического материала. На практических занятиях с проблемной ситуацией обучающиеся сталкиваются при закреплении теоретического материала и решении задач. Кроме того, непременным компонентом проблемно-ориентированного обучения является целенаправленно организуемая внеаудиторная самостоятельная работа обучающихся по выполнению проблемных заданий и овладению новыми разделами дисциплины.

Проанализируем возможные типы проблемных ситуаций, и приведем примеры их реализации при изучении математики [4].

Проблемная ситуация возникает в результате выявления противоречия между новой информацией и теми знаниями и представлениями, которые ранее сформировались у обучающихся. В этом случае задача преподавателя состоит в том, чтобы подвести обучающихся к необходимости вводить новые понятия, а также расширять или изменять имеющиеся представления для устранения выявленного противоречия. Причем это не является искусственным методическим приемом - именно так научные понятия и возникали, о чем свидетельствует история науки. Обучающиеся должны понимать: то, что мы знаем и умеем, возникло, в свое время, в результате разрешения тех или иных проблемных ситуаций. Именно так, например, возникло понятие производной в результате решения И. Ньютоном проблемы определения закона неравномерного прямолинейного движении, а Г. Лейбницем - проблемы, связанной с составлением уравнения касательной прямой к произвольной кривой. Следовательно, проблемный подход к изложению учебного материала необходимо согласовывать с историческим подходом, и принцип историзма должен быть одним из 
принципов, составляющих основу современного математического образования в вузе.

На лекциях проблемная ситуация создается путем формулирования теоретических утверждений в виде задач, для решения которых требуется трансформация имеющихся у обучающихся знаний и освоение новых разделов дисциплины. Так реализуется одна из основных целей обучения - побуждение обучающихся к самостоятельным открытиям. Например, теоретическое понятие определенного интеграла вводится по результатам решения геометрической задачи о площади криволинейной трапеции и физической задачи о количестве электричества, протекшего через поперечное сечение проводника, а понятие дифференциального уравнения - исходя из решения задач о законе неравномерного прямолинейного движения или задачи о силе тока в электрическом контуре.

Проблемная ситуация может быть создана в результате применения эвристической операции «установление аналогий» между свойствами известных понятий с последующим применением эвристической операции «обобщение» с целью введения нового понятия. Например, знакомство обучающихся с комплексными числами позволяет по аналогии ввести понятие кватернионов как упорядоченной пары комплексных чисел и чисел Кэли как упорядоченной пары кватернионов. Выявление сходства в свойствах операций сложения и умножения на число в различных множествах (геометрические векторы, матрицы, функции) позволяет ввести обобщенное понятие «линейное пространство». Задача о разложении функции в обобщенный ряд Фурье, например в ряд Котельникова, ставится и решается как обобщение задачи о разложении функции по ортогональной системе тригонометрических функций.

Проблемная ситуация возникает, когда самостоятельное изучение новых разделов учебной дисциплины выстраивается как применение и расширение уже имеющихся знаний и умений. Такой подход опирается на положение Дж. Брунера: «Оптимально построенный учебный процесс отражает предшествующий материал и позволяет учащемуся делать обобщения, выходящие за пределы данной темы» [1]. Подобным образом, например, организуется самостоятельное изучение обучающимися криволинейного интеграла первого рода (по длине дуги) как конкретизация изученного ранее понятия интеграла по произвольной области и расширение сферы его практического применения.

В ходе математической подготовки специалистов технического профиля особое внимание необходимо уделять решению задач. Традиционными функциями задач являются: овладение системой математических знаний, умений и навыков, развитие математической культуры и мышления, активизация самостоятельной познаватель- ной деятельности. Однако в условиях реализации проблемно-ориентированного обучения с использованием задач осуществляется и введение новых теоретических положений и методов.

Заслуживает внимание предлагаемый Жунисбековой Д.А. и ее коллегами подход к трактовке задачи проблемного характера как задачи, способ решения которой обучающемуся неизвестен, либо как задачи, для решения которой в курсе математики не содержится конкретного правила. Такие задачи для своего решения требуют гибкости и критичности мышления, изобретательности, распределения внимания, выработки новых способов действий. И в силу того, что таким задачам принадлежит особая роль в развитии творческой личности, вопросу формирования у обучающихся умения решать такие задачи необходимо уделять больше внимания (о чем свидетельствуют данные многочисленных исследований) [3].

Приобщению обучающихся к эвристической деятельности способствует не только решение достаточно сложных проблемных задач, но и решение стандартных задач, организуемое проблемно-ориентированным способом, когда реализуются все фазы решения учебной проблемы и используются соответствующие эвристические операции и приемы. Таким образом, например, полезно выстраивать решение задач аналитической геометрии.

Важно отметить, что эффективность проблемно-ориентированного обучения решению учебных задач существенно зависит от правильной их классификации и целенаправленного использования в учебном процессе.

Реализуя идеи проблемного обучения в курсе математики, полезно помнить слова Д. Пойа: «Математическое мышление не базируется на одних лишь аксиомах и строгих доказательствах, а включает в себя, помимо этого, и многое другое: обобщение рассмотренных случаев, применение индукции, использование аналогии ... нужно всеми средствами обучать искусству доказывать, не забывая при этом также об искусстве догадываться» [15].

Главная ценность проблемно-ориентированного обучения состоит в том, что обучающиеся получают возможность сравнивать, наблюдать, обсуждать факты, делать выводы; убеждаются в том, что не на каждый вопрос есть готовый ответ, что ответ может быть неоднозначным, что каждый из них имеет право искать и находить свой ответ, отстаивать свое мнение [3].

Зимина О.В., говоря о проблемном обучении, утверждает: «у нас просто нет иных способов пробудить интерес студентов к предмету и усилить их мотивацию к учебе. Развивая весьма категоричное положение психологов о том, что «если в системе мотивов учащегося полностью отсутствуют познавательные мотивы, то его деятель- 
ность нельзя назвать учебной» (Е.И. Машбиц), можно сказать, что обучение, которое не является проблемным, вообще нельзя назвать обучением» [4].

Вместе с тем, необходимо помнить о том, что в условиях массового высшего образования остается актуальной потребность выявления оптимальных возможностей синтеза в педагогической практике идей проблемного, эвристического и «традиционного» обучения. Важно, чтобы включение в традиционную дидактическую систему принципов и методов проблемного обучения и (или) эвристического обучения не разрушало равновесия в этой системе, то есть одни дидактические принципы не должны доминировать в ущерб другим и тем более вступать друг с другом в конфликт. Заметим, что это вполне согласуются с положением Я.А. Коменского о том, что «... искусство обучения не требует ничего иного, кроме искусного распределения времени, предметов и методов» [5].

Таким образом, можно сделать вывод о том, что использование идей проблемного обучения при организации учебно-познавательной деятельности интенсифицирует прочесс приобщения обучающихся к поисковой, исследовательской деятельности, развивает их эвристические способности в силу того, что интеллектуальные усилия, которые предпринимают обучающиеся при нахождении способа решения проблемы, их активная мыслительная деятельность в процессе решения (особенно если это решение оптимальное) формирует и оставляет в памяти алгоритм, который в дальнейшем срабатывает как метод при решении проблем аналогичного класса. В результате возникает ментальный (умственный) опыт, на основании которого, обучающиеся совершенствуют эвристические умения анализировать, сравнивать, систематизировать, обобщать. Вместе с тем, растет познавательный интерес и мотивация, активизируется учебно-познавательная деятельность, увеличивается ее эвристическая составляющая, реализуется исследовательский потенциал, развиваются такие личностные качества обучающегося, как настойчивость в достижении поставленной цели, воля; формируется потребность и необходимость интеллектуально-личностного совершенствования, развития творческого потенциала.

Итак, проблемное обучение представляет собой систему методов, средств, направленных на обеспечение возможности творческого участия обучающегося, что выражается в становлении познавательной самостоятельности, в процессе усвоения новых знаний, формирование творческого мышления, развития творческих способностей через призму созданных проблемных ситуаций.

Эвристическое обучение - обучение, ставящее целью конструирование обучающимся собственного смысла, целей и содержания образования, а также процесса его организации, диагностики и осознания. Проблемно-эвристическое обучение - обучение, основанное на органичном объединении принципов и методов проблемного и эвристического обучений.

В условиях проблемно-эвристического обучения развитие активности в умственной деятельности обучающихся можно характеризовать как переход от действий, стимулируемых заданиями педагога, к самостоятельной постановке вопросов; от действий, связанных с выбором уже известных путей и способов, - к самостоятельным поискам решения задач и дальше - к выработке умения самостоятельно видеть проблемы и исследовать их.

Культивируемый в проблемно-эвристическом обучении исследовательский метод - это такая организация учебной работы, при которой обучающиеся знакомятся с научными методами добывания знаний и, осваивая доступные им элементы научных методов, овладевают умением самостоятельно добывать новые знания, планировать поиск и открывать новую для себя зависимость или закономерность.

В процессе обучения важно последовательно переводить обучающихся на более высокий уровень проблемно-эвристического обучения. Разумеется (и это важно подчеркнуть), умения видеть, формулировать и решать проблему не складываются стихийно, как спонтанное развитие изначально заложенных тенденций. Это результат обучения.

По мнению известного отечественного дидакта И.Я. Лернера, проблемное обучение должно осуществляться лишь при изучении части учебного материала, что и позволяет творчески перерабатывать информацию, полученную как в проблемном, так и в «непроблемном» обучении [9].

Безусловно, проблемный метод нельзя считать универсальным.

Проблемно-эвристическое обучение направлено на развитие творческого потенциала и формирование творческих структур, усвоение знаний средствами творческих заданий, проектов и освоение способов деятельности; творческое овладение методами современной науки.

Реализация проблемно-эвристического обучения способствует развитию внимания, наблюдательности, нестандартного мышления, активизации учебно-познавательной деятельности обучающихся, проявлению независимости в выборе способов и методов деятельности, инициативности, решительности, критичности и самокритичности. Самостоятельность приобретаемых знаний обеспечивает их прочность [18]. 
В отличие от других видов обучения, проблемно-эвристическое имеет преимущества, так как:

1. учит мыслить логично, научно, диалектически, творчески;

2. учебный материал становится более доказательным, что влечет превращение знаний в убеждения;

3. эмоционально вызывает интеллектуальные чувства такие, как чувство удовлетворения, чувство уверенности в своих возможностях и силах, формируя тем самым у обучающихся интерес к научному знанию;

4. не позволяет легко забыть самостоятельно добытые знания, а если они забыты, то могут быть быстрее восстановлены.

Проблемно-эвристическое обучение связано с исследовательской деятельностью, поэтому выполняемые задания обучающимися растянуты во времени. Вовлекаясь в исследовательский процесс решения творческой задачи или проблемы, обучающийся постоянно размышляет о ней до тех пор, пока не получит желаемого результата. За счет такого подхода формируются прочные знания, навыки и умения [18].

К недостаткам проблемно-эвристического обучения можно отнести то, что оно всегда вызывает затруд- нение у обучающегося в учебном процессе, поэтому на его осмысление и поиски путей решения уходит значительно больше времени, чем при «традиционном» обучении. Кроме того, разработка технологии проблемно-эвристического обучения требует от преподавателя большого педагогического мастерства и времени. Видимо, именно эти обстоятельства не позволяют широко применять проблемно-эвристическое обучение. Вместе с тем такое обучение отвечает требованиям современности: обучать исследуя, исследовать обучая. Только так и можно формировать творческую личность, то есть реализовывать основную задачу педагогического труда.

Таким образом, результатом всей системы педагогических мероприятий при проблемно-эвристическом обучении является развитие продуктивного и эвристического (творческого) мышления. Продуктивность мышления обучающихся выражается в способности решить конкретную задачу определенной трудности на основе знакомства с фактическим материалом. В процессе интеллектуальной деятельности эвристическое мышление способно создать и закрепить определенную систему средств для решения будущих задач, что обусловливает широту и разнообразие решаемых задач.

\section{ЛИТЕРАТУРА}

1. Брунер, Дж. Психология познания. - М.: Прогресс, 1977. - 123 с.

2. Выготский, Л.С. Собрание сочинений. - М.: Педагогика, 1984. Т.4., 432 с.

3. Жунисбекова, Д.А. Некоторые проблемы методики обучения математике с использованием проблемных ситуаций / Д.А. Жунисбекова, Х.А. Аширбаев, Г.А. Такибаева, К.Ж. Рустемова, А.И. Джугамалиева. - Южно-Казахский государственный университет им. М. Ауэзова, Шымкент. Международный журнал прикладных и фундаментальных исследований. № 1, 2016. с. 68-71.

4. Зимина, 0.В. Проблемное обучение высшей математике в техническом вузе / 0. В. Зимина // Математика в Высшем 0бразовании. - 2006. - № 4. - С. 55-77.

5. Коменский, Ян Амос. Избранные педагогические сочинения / Ян Амос Коменский. - М.: Педагогика. - 1982. - 231с.

6. Кудрявцев, Т.В. Решение задач как средство изучения технических знаний / Т.В. Кудрявцев, А.Я. Штеймец // Вопросы психологии. № 3, 1973. - С. 73-83

7. Кудрявцев, Л.Д. Современная математика и ее преподавание / Л.Д. Кудрявцев. - М.: Наука: Главная редакция физико-математической литературы, $1980 .-144$ с.

8. Лернер, И.Я. Дидактические основы методов обучения / И.Я. Лернер. - М.: Педагогика, 1981. - 185 с.

9. Лернер, И.Я. Проблемное обучение / И.Я. Лернер. - М.: Знание, 1974. - 64 с.

10. Матюшкин, А.М. Проблемные ситуации в мышлении и обучении. - М.: Педагогика, 1972.

11. Махмутов, М.И. Проблемное обучение. Основные вопросы теории / М.И. Махмутов. - М.: Педагогика, 1975. - 367с.

12. Машбиц, Е.И. Психолого-педагогические проблемы компьютеризации обучения. - М.: Педагогика, 1988. - 234 с.

13. Оконь, В. Введение в общую дидактику / В. Оконь. - М.: Высшая школа, 1990. 381 с.

14. Осминин, К.А. Практические подходы к внедрению системы менеджмента качества в образовательном учреждении // Alma mater. - 2014. - № 7. - С. 31-36.

15. Пойя, Д. Математическое открытие / Д. Пойя. - М.: Наука, 1976. - 448 с.

16. Разумовский, В. Г. Развитие творческих способностей учащихся. - М.: Просвещение, 1975. - 272 с.

17. Рубинштейн, С.Л. Проблемы способностей и вопросы психологической теории. Проблемы общей психологии. - М.: 1973. - 227 с.

18. Садыкова, Л.В. Развитие познавательной активности студентов через организацию проблемно-поисковой деятельности на занятиях по математике / Л.В. Садыкова // Педагогика: традиции и инновации: материалы IV международной научной конференции (г. Челябинск, декабрь 2013 г.). — Челябинск: Два комсомольца, 2013. - С. 163-169. 